\title{
PENGARUH VARIAS I ANYAMAN LATERAL SERAT CANTULA (AGAVE CANTULA ROXB) PADA TEXTILE REINFORCED CONCRETE (TRC) TERHADAP KUAT TEKAN BETON
}

\author{
Edy Purwanto(1), SA Kristiawan(2), Dhanes Prabaswara(3) \\ 1)Pengajar Fakultas Teknik, Prodi Teknik Sipil, Universitas Sebelas Maret \\ 2)Pengajar Fakultas Teknik, Prodi Teknik Sipil, Universitas Sebelas Maret \\ 3)Mahasiswa Fakultas Teknik, Prodi Teknik Sipil, Universitas Sebelas Maret \\ Jalan Ir. Sutami No.36A Surakarta 57126.Telp.0271647069. Email: dhanes17@gmail.com
}

\begin{abstract}
The use of reinforced concrete has become the principal boosters material as the structure of a building. Damaged concrete and degradation power can be improved to restore or add to the strength and their ability in bearing the original structure. Textile reinforced concrete (TRC) is composite consisting of textile industry as one of that serves as reinforcement and fine-grained concrete as a matrix. Textile reinforcement generally used the non-nature material like fiber glass (AR), aramid, basalt and carbon fabrics. There are also natural materials that can be used in textile reinforcement, for example like cantula fibers. Agave Cantula Roxb is a natural fiber that has bigh mechanical ability. The Textile Reinforced Concrete (TRC) used in this study consisted of a concrete cylinder as a matrix and reinforcement in the form of woven cantula fibers which were confined in concrete which had a variation of the lateral reinforcement direction according to the specified dimensions. That variation is used to find out the most optimal effect on the compressive strength of concrete. Variations in woven cantula fiber used are $10 \mathrm{~mm} \times 10 \mathrm{~mm}, 15 \mathrm{~mm} \times 10 \mathrm{~mm}, 20 \mathrm{~mm} \times 10 \mathrm{~mm}$. Testing on textile reinforced concrete is done at 28 days. The results showed that the largest actual compressive strength ( $f c)$ value was in the test object with TRC 100 code, amounting to $18.33 \mathrm{MPa}$. In addition, an increase in strength in the concrete that has been confined by cantula fibers to normal concrete. The largest percentage increase in compressive strength value is on the test object with TRC 100 code, which is $1.89 \%$.
\end{abstract}

Keywords : Textile Reinforced Concrete, Cantula Fiber, Variation in Woven Fiber, Compressive Strength.

\begin{abstract}
ABSTRAK
Penggunaan beton bertulang telah menjadi material pokok sebagai struktur penguat suatu bangunan. Beton yang mengalami kerusakan maupun degradasi kekuatan tersebut dapat diperbaiki untuk mengembalikan atau menambah kekuatan dan kemampuannya dalam menopang struktur seperti sedia kala. Textile Reinforced Concrete (TRC) merupakan komposit yang terdiri dari tekstil yang berfungsi sebagai reinforcement dan fine-grained concrete sebagai matriks. Textile reinforcement yang digunakan umumnya berupa material non-nature, seperti serat kaca tahan alkali (AR), aramid, basalt dan carbon fabrics. Terdapat pula material alam yang dapat digunakan pada textile reinforcement, salah satunya yaitu serat cantula. Agave Cantula Roxb merupakan serat alam yang memiliki kemampuan mekanik yang tinggi. Textile Reinforced Concrete (TRC) yang digunakan pada penelitian ini terdiri dari silinder beton sebagai matrik dan reinforcement berupa anyaman serat cantula yang dikekang pada beton yang memiliki variasi arah penulangan lateral sesuai dengan dimensi yang ditentukan. Variasi anyaman tersebut digunakan untuk mengetahui pengaruh yang paling optimal pada kuat tekan beton. Variasi anyaman serat cantula yang digunakan adalah $10 \mathrm{~mm} \times 10 \mathrm{~mm}$, $15 \mathrm{~mm} \times 10 \mathrm{~mm}, 20 \mathrm{~mm} \times 10 \mathrm{~mm}$. Pengujian pada Textile Reinforced Concrete dilakukan pada umur 28 hari. Hasil penelitian menunjukkan bahwa nilai kuat tekan aktual ( $\mathrm{fc}$ ) yang terbesar yaitu pada benda uji dengan kode TRC 100 , sebesar 18,33 MPa. Selain itu, terjadi peningkatan kekuatan pada beton yang telah terkekang oleh serat cantula terhadap beton normal. Prosentase peningkatan nilai kuat tekan terbesar yaitu pada benda uji dengan kode TRC 100 sebesar $1,89 \%$.
\end{abstract}

Kata Kunci : Textile Reinforced Concrete, Serat Cantula, Variasi Anyaman Serat, Kuat Tekan.

\section{PENDAHULUAN}

\section{Latar Belakang}

Penggunaan beton bertulang telah menjadi material pokok sebagai struktur penguat suatu bangunan. Hal ini dikarenakan beton itu sendiri memiliki keunggulan karakteristik dibandingkan dengan bahan struktur lain, diantaranya seperti durabilitas yang baik, kuat tekan yang tinggi, serta biaya yang relatif terjangkau. Tetapi jika terdapat kesalahan dalam pembuatannya maka dapat menyebabkan kerusakan pada struktur bangunan, baik dalam skala kecil maupun besar. Faktor bencana alam seperti gempa bumi juga dapat menyebabkan kerusakan struktur pada bangunan, terutama kolom dan balok. Beton yang mengalami kerusakan maupun degradasi kekuatan tersebut dapat 
diperbaiki untuk mengembalikan atau menambah kekuatan dan kemampuannya dalam menopang struktur seperti sedia kala.

Salah satu alternatif dan inovasi untuk perbaikan dan perkuatan beton konvensional adalah penggunaan perkuatan Textile Reinforced Concrete, yang menghasilkan peningkatan daya tahan dan keandalan dalam konstruksi teknik sipil (Triantafillou, 2018). Textile Reinforced Concrete (TRC) merupakan material lapisan komposit terdiri finegrained concrete dan anyaman serat textile sebagai reinforcement.

Untuk sekarang ini, metode yang sudah ada di lapangan yaitu menggunakan serat karbon sebagai material pengekang beton. Namun, faktor biaya menjadi kendala dari penggunaan material serat karbon. Oleh karena itu, saat ini peneliti mencoba menggunakan material lain yaitu serat cantula yang memiliki biaya relatif murah. Pengaplikasiannya yaitu dengan cara menempelkan anyaman serat cantula pada silinder beton.

\section{TINJAUAN PUSTAKA}

\section{Serat Cantula}

Serat cantula adalah salah satu serat alam yang berasal dari ekstraksi daun tanaman cantula. Tanaman ini banyak tumbuh di daerah Kulonprogo, DIY sampai dengan Temanggung, Jawa Tengah. Tanaman cantula memiliki daun yang kaku dengan panjang $100-175 \mathrm{~cm}$ dengan duri di sepanjang tepi daunnya. Untuk mendapatkan serat dari cantula, metode yang dipakai adalah metode ekstraksi (extraction). Pada proses ekstraksi, daun yang akan diambil seratnya dijepit dengan menggunakan alat khusus lalu ditarik pada salah satu ujungnya, sehingga seratnya terpisah (Dody Ariawan, dkk. 2009). Pada penelitian Raharjo (2002) menyatakan bahwa serat Agave Cantula Roxb merupakan serat alam yang memiliki kemampuan mekanik yang tinggi.

Penggunaan serat pada beton dihitung berdasar rasio dalam $/ / d$ dan volume fraction. Pada penelitian ini, serat digunakan sebagai pengekang bersama dengan PMM.

\section{Karakteristik TRC}

Pada dasarnya, Textile Reinforced Concrete (TRC) merupakan komposit yang terdiri dari dua komponen yaitu, tekstil yang berfungsi sebagai reinforcement dan concrete yang berfungsi sebagai matriks. Reinforcement pada tekstil berfungsi untuk memperkuat struktur beton dengan memberikan dukungan kuat tarik, penambahan kuat tekan, dan tegangan geser. Penerapan dari TRC sebagai perkuatan telah berhasil dibuktikan oleh beberapa proyek penelitian. Namun, penerapannya untuk sebagai teknisasi bahan dasar masih perlu banyak penyelidikan. Satu langkah penting untuk mencapai tujuan ini adalah dengan memodelkan perilaku mekanik TRC untuk aplikasi numerik ke dalam situasi nyata.

\section{Kuat Tekan}

Menurut SNI 03-1974-2011 kuat tekan beton adalah besarnya beban per satuan luas, yang dapat menyebabkan benda uji yang berupa beton hancur. Beban tersebut berupa gaya tekan yang dihasilkan oleh mesin tekan. Benda uji yang digunakan berbentuk silinder dengan tinggi $150 \mathrm{~mm}$ dan diameter $95 \mathrm{~mm}$. Umur benda uji yang digunakan adalah 28 hari.

Perhitungan kuat tekan beton normal diperoleh dari rumus:

$$
f^{\prime} c o=\frac{P \max }{A}
$$

Dimana:

f'co : Kuat tekan beton normal (MPa)

Pmax : Beban maksimum $(\mathrm{N})$

A : Luas permukaan yang dibebani $\left(\mathrm{mm}^{2}\right)$

Perhitungan kuat tekan beton terkekang menggunakan model persamaan dari Pham \& Hadi, (2014) :

$$
\begin{gathered}
\frac{f_{c c}^{\prime}}{f_{c o}^{\prime}}=1+k_{1} \frac{f_{l}}{f_{c o}^{\prime}} \\
f_{l}=\frac{2 f_{f} t}{d}
\end{gathered}
$$




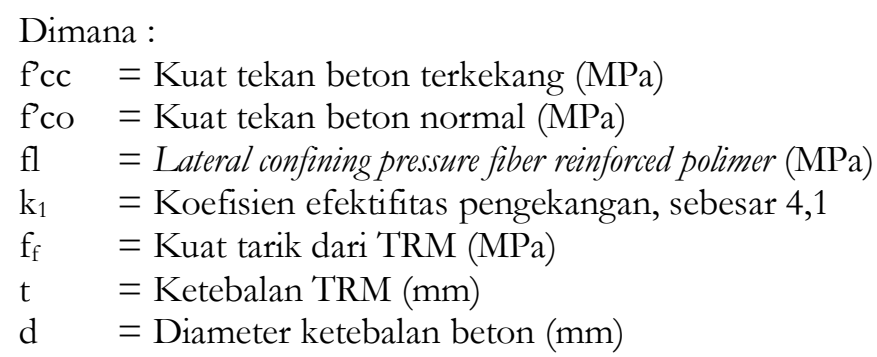

\section{METODE PENELITIAN}

\section{Material}

Seperti yang telah diketahui, Textile Reinforced Concrete (TRC) merupakan komposit yang terdiri dari dua komponen yaitu, tekstil yang berfungsi sebagai reinforcement dan concrete yang berfungsi sebagai matriks. Material penyusun TRC antara lain:

1. Agregat halus yang digunakan adalah pasir yang memenuhi syarat lolos saringan 1,18 mm.

2. Agregat kasar yang digunakan adalah batu pecah yang memiliki ukuran maksimum $20 \mathrm{~mm}$.

3. Semen dengan jenis Pozzolan Portland Concrete (PPC).

4. Accelerator SIKACIM®. Accelerator sebanyak 50\% dari jumlah air yang digunakan untuk membuat mortar. Accelerator berguna untuk mempercepat proses pengerasan pada mortar dan meningkatkan kekuatan mortar pada umur awal.

5. Envirotac polymer. Polimer merupakan bahan tambah yang mempunyai kemampuan sebagai bahan perekat pada mortar.

6. Anyaman serat cantula, dengan variasi anyaman $10 \mathrm{~mm} \times 10 \mathrm{~mm}, 15 \mathrm{~mm} \times 10 \mathrm{~mm}, 20 \mathrm{~mm} \times 10 \mathrm{~mm}$.

7. Superplasticizer, yang berfungsi untuk meningkatkan workability pada benda uji.

\section{Benda Uji}

Benda uji yang digunakan pada penelitian ini berbentuk silinder beton yang berumur 28 hari dengan diameter 75 $\mathrm{mm}$ dan tinggi $150 \mathrm{~mm}$. Pengujian benda uji dilakukan dengan cara uji tekan langsung menggunakan mesin UTM. Reinforcement yang digunakan adalah anyaman serat cantula yang dikekang pada beton menggunakan Polymer Modified Mortar (PMM) dengan ketebalan $10 \mathrm{~mm}$. Variasi matriks yang diteliti berupa anyaman serat cantula pada Textile Reinforced Concrete (TRC). Variasi anyaman serat cantula yang digunakan yaitu $10 \mathrm{~mm}$ x10 mm, $15 \mathrm{~mm}$ x 10 $\mathrm{mm}, 20 \mathrm{~mm} \times 10 \mathrm{~mm}$.

\section{HASIL DAN PEMBAHASAN}

Hasil Uji Kuat Tarik

Hasil uji kuat tarik didapatkan dari penelitian Firman (2019) menggunakan Polymer Modified Mortar (PMM) dengan bentuk jam pasir. Berikut adalah hasil uji kuat tarik pada Tabel 1 berikut.

Tabel 1 Hasil Uji Kuat Tarik Langsung Polymer Modified Mortar berserat cantula

\begin{tabular}{cc}
\hline Kode & Kuat Tarik (Ff) (MPa) \\
\hline \hline TRC 100 & 1,01 \\
\hline TRC 051 & 1 \\
\hline TRC 002 & 0,93
\end{tabular}

Dari hasil uji tarik diatas didapatkan nilai kuat tekan lateral beton terkekang (fl). Berikut ini adalah nilai kuat tekan lateral beton terkekang (fl) yang tertera pada Tabel 2 berikut ini:

Tabel 2 Rekapitulasi Perhitungan Kuat Tekan Lateral

\begin{tabular}{|c|c|c|c|c|}
\hline Kode & $\mathrm{d}(\mathrm{mm})$ & $\mathrm{t}(\mathrm{mm})$ & $\begin{array}{c}\text { Kuat Tarik (Ff) } \\
\text { (MPa) }\end{array}$ & $\begin{array}{c}\text { Kuat Tekan } \\
\text { Lateral (F1) } \\
(\mathrm{MPa})\end{array}$ \\
\hline TRC 100 & 75 & 10 & 1.07 & 0.284 \\
\hline TRC 051 & 75 & 10 & 1 & 0,267 \\
\hline TRC 002 & 75 & 10 & 0.93 & 0,249 \\
\hline
\end{tabular}




\section{Uji Kuat Tekan}

Pengujian kuat tekan beton dilakukan untuk mengetahui beban optimum yang dapat ditahan oleh beton hingga beton retak atau hancur. Pengujian dilakukan menggunakan Universal Testing Machine. Tahapan pengujian yang dilakukan yaitu :

1. Mengukur dimensi benda uji sebelum dilakukan pengujian

2. Meletakkan benda uji pada Universal Testing Machine

3. Menyalakan alat dan memulai pengujian

4. Membaca hasil kuat tekan pada komputer hingga benda uji runtuh

5. Setelah runtuh, alat dimatikan dan membereskan benda uji

\section{Uji Kuat Tekan Aktual}

Nilai kuat tekan aktual didapatkan dari hasil uji kuat tekan. Rekapitulasi hasil uji kuat tekan dapat dilihat pada Tabel 3 dibawah ini:

Tabel 3 Rekapitulasi Perhitungan Kuat Tekan Beton Normal

\begin{tabular}{|c|c|c|c|c|c|c|}
\hline & Kode & $P(k N)$ & $\mathrm{d}(\mathrm{mm})$ & $A\left(\mathrm{~mm}^{2}\right)$ & F'c (MPa) & $\begin{array}{l}\text { F'c Rata- } \\
\text { rata (MPa) }\end{array}$ \\
\hline$\overline{\mathrm{A}}$ & "TRC 000 & 7272.5 & 75 & 44419.64 & 16.40 & \multirow{5}{*}{17,99} \\
\hline $\mathrm{B}$ & TRC 000 & 75 & 75 & 4419.64 & 16.97 & \\
\hline $\mathrm{C}$ & TRC 000 & 67.5 & 75 & 4419.64 & 15.27 & \\
\hline $\mathrm{D}$ & TRC 000 & 102.5 & 75 & 4419.64 & 23.19 & \\
\hline $\mathrm{E}$ & TRC 000 & 80 & 75 & 4419.64 & 18.10 & \\
\hline A & TRC 100 & 72.5 & 75 & 4419.64 & 16.40 & \multirow{5}{*}{18,33} \\
\hline $\mathrm{B}$ & TRC 100 & 90 & 75 & 4419.64 & 20.36 & \\
\hline $\mathrm{C}$ & TRC 100 & 75 & 75 & 4419.64 & 16.97 & \\
\hline $\mathrm{D}$ & TRC 100 & 95 & 75 & 4419.64 & 21.49 & \\
\hline $\mathrm{E}$ & TRC 100 & 72.5 & 75 & 4419.64 & 16.40 & \\
\hline $\mathrm{A}$ & TRC 051 & 70 & 75 & 4419.64 & 15.84 & \multirow{5}{*}{18,21} \\
\hline $\mathrm{B}$ & TRC 051 & 72.5 & 75 & 4419.64 & 16.40 & \\
\hline $\mathrm{C}$ & TRC 051 & 90 & 75 & 4419.64 & 20.36 & \\
\hline $\mathrm{D}$ & TRC 051 & 90 & 75 & 4419.64 & 20.36 & \\
\hline $\mathrm{E}$ & TRC 051 & 80 & 75 & 4419.64 & 18.10 & \\
\hline A & TRC 002 & 77.5 & 75 & 4419.64 & 17.54 & \multirow{5}{*}{18,10} \\
\hline B & TRC 002 & 80 & 75 & 4419.64 & 18.10 & \\
\hline $\mathrm{C}$ & TRC 002 & 85 & 75 & 4419.64 & 19.23 & \\
\hline $\mathrm{D}$ & TRC 002 & 82.5 & 75 & 4419.64 & 18.67 & \\
\hline $\mathrm{E}$ & TRC 002 & 75 & 75 & 4419.64 & 16.97 & \\
\hline
\end{tabular}

\section{Kuat Tekan Permodelan}

Nilai kuat tekan permodelan didapatkan dari pengolahan data hasil uji kuat tekan beton normal (fco).

Rekapitulasi perhitungan kuat tekan beton terkekang dari masing-masing benda uji dapat dilihat pada Tabel 4 di bawah ini: 
Tabel 4 Rekapitulasi Perhitungan Kuat Tekan Beton Permodelan

\begin{tabular}{cccc} 
Kode & $\mathbf{f}^{\prime} \mathbf{c o}(\mathbf{M p a})$ & $\mathbf{f l}(\mathbf{M p a})$ & $\mathbf{F}^{\prime} \mathbf{c c}(\mathbf{M p a})$ \\
\hline \hline TRC 100 & 17.99 & 0.284 & 19.15 \\
\hline TRC 051 & 17.99 & 0.267 & 19.08 \\
\hline TRC 002 & 17.99 & 0.249 & 19.01
\end{tabular}

Rekapitulasi Hasil Uji Kuat Tekan

Rekapitulasi perhitungan kuat tekan aktual dan permodelan disajikan pada Tabel $\mathbf{5}$ di bawah ini:

Tabel 5 Rekapitulasi Perhitungan Kuat Tekan Aktual dan Permodelan

\begin{tabular}{|c|c|c|c|c|c|}
\hline \multirow{2}{*}{ Kode } & \multirow{2}{*}{$\mathrm{f}^{\prime} \operatorname{co}(\mathrm{MPa})$} & \multicolumn{2}{|c|}{ F'cc (MPa) } & \multirow{2}{*}{$\begin{array}{c}\text { Perbandingan } \\
f^{\prime} c / f^{\prime} c c\end{array}$} & \multirow{2}{*}{$\begin{array}{c}\text { Peningkatan } \\
\text { Kekuatan (\%) }\end{array}$} \\
\hline & & Aktual & Permodelan & & \\
\hline TRC 100 & 17.99 & 18.33 & 19.15 & 0.96 & 1.89 \\
\hline TRC 051 & 17.99 & 18.21 & 19.08 & 0.95 & 1.26 \\
\hline TRC 002 & 17.99 & 18.10 & 19.01 & 0.95 & 0.63 \\
\hline
\end{tabular}

Dari tabel di atas diketahui bahwa nilai kuat tekan aktual ( $\mathrm{f}$ c) yang terbesar yaitu pada benda uji dengan kode TRC 100, sebesar 18,33 MPa. Hal ini dikarenakan jarak anyaman serat kantula pada arah lateral paling kecil dibandingkan dengan benda uji yang lainnya. Dapat dilihat pula terjadi peningkatan kekuatan pada beton yang telah terkekang oleh serat cantula terhadap beton normal. Prosentase peningkatan nilai kuat tekan terbesar yaitu pada benda uji dengan kode TRC 100 sebesar 1,89\%

\section{KESIMPULAN}

Berdasarkan data hasil pengujian, analisis data, dan pembahasan mengenai kuat tekan Textile Reinforced Concrete dengan anyaman serat cantula, dapat ditarik kesimpulan sebagai berikut.

1. Nilai kuat tekan aktual (f') yang terbesar yaitu pada benda uji dengan kode TRC 100, sebesar 18,33 MPa. Hal ini dikarenakan jarak anyaman serat kantula pada arah lateral paling kecil dibandingkan dengan benda uji yang lainnya. Jarak anyaman memberikan dampak pada kuat tekan beton, semakin kecil jarak anyaman maka akan semakin tinggi pula nilai kuat tekan yang dihasilkan.

2. Terdapat peningkatan kekuatan pada beton yang telah terkekang oleh serat cantula terhadap beton normal. Prosentase peningkatan nilai kuat tekan terbesar yaitu pada benda uji dengan kode TRC 100 sebesar 1,89\%. Dapat disimpulkan bahwa anyaman serat cantula yang digunakan memberi dampak terhadap peningkatan kuat tekan confined concrete

\section{REFERENSI}

Ariawan, Dody, R. Wijang Wisnu, Windiarto. 2009. Pengarub Model Anyaman 3d Serat Cantula Terbadap Karakteristik Serapan Bunyi Komposit Unsaturated Polyester Resin (Uprs) - Cantula 3d. Surakarta: Universitas Sebelas Maret Surakarta

Kartika, Febiana Yoda. 2018. Pengaruh Volume Fraction dan Aspek Rasio Serat Agave Cantula Roxb Dengan Polymer Modified Mortar Terhadap Kuat Tekan dan Kuat Tarik Langsung. Surakarta: Universitas Sebelas Maret Surakarta.

Pham, T.M. \& Hadi, M. N. S. 2014. Confinement model for FRP confined normal-and high-strength concrete circular coloumns. Construction and Building Material

Pratama, Firman.2019. Analisis Modulus Elastisitas dan Kuat Tarik Pada Polymer Modified Mortar (PMM) dengan Penambahan Serat Cantula (Agave Cantula Roxb). Surakarta: Universitas Sebelas Maret Surakarta.

Sasmito, Ashar Natsir.2018. Pengaruh Reinforcement Ratio Serat Cantula (Agave Cantula Roxb) Terhadap Kuat Tarik Textile Reinforced Concrete. Surakarta: Universitas Sebelas Maret Surakarta.

Raharjo, Wijang W. 2015. Sifat Tarik dan Lentur Komposit rHDPE/Serat Cantula dengan Variasi Panjang Serat. Banjarmasin: Proceeding Seminar Tahunan Teknik Mesin XIV.

SNI 03-2847-2002. 2002. Tata Cara Perhitungan Struktur Beton untuk Bangunan Gedung. Bandung : Badan Standarisasi Nasional.

SNI 03-1974-2002. 2002. Metode Penguïan Kuat Tekan Beton. Jakarta : Badan Standarisasi Nasional.

Triantafillou, P.E. 2007. Textile-Reinforced Mortar (TRM) versus FRP Confinement in Reinforced Concrete Columns. ACI Structural Journal. 
Triantafillou, P.E. 2018. Strengthening of Concrete Structures with Textile Reinforced Mortars. State-ofthe-Art Review. ASCE.

Tsesarsky, Michael. 2013 Textile reinforced concrete (TRC) shells for strengthening and retrofitting of concrete elements: influence of admixtures. Rilem 